\title{
MANAJEMEN BERBASIS \\ SEKOLAH DALAM PELAKSANAAN EKSTRAKURIKULER DI SMA NEGERI 2 BOJONEGORO
}

\author{
Hardiyanto Ismail \\ Program Studi Manajemen Pendidikan Pasca Sarjana Unesa \\ hardiyanto ismail@yahoo.com
}

\begin{abstract}
This study attempts to described School-Based Management in the implementation of the extracurricular in Senior High School 2 Bojonegoro which discusses : 1) Management the curriculum In Senior High School 2 bojonegoro; 2) Management of extracurricular for the implementation of School-Based Management in Senior High School 2 Bojonegoro; 3 ) The execution of extracurricular for the implementation of management the curriculum in public Senior High School 2 Bojonegoro. The kind of research is research descriptive with the design study cases.Technique data collection is observation, interview, and documentation.Data sources is The Headmaster, Curriculum Teacher, Manager of student, and extracurricular Teachers. Checking the validity of by means of triangulation. The results of the study that is the curriculum is held in Senior High School 2 Bojonegoro is 2013 curriculum teacher .Responsible for extracurricular management in Senior High School 2 Bojonegoro is a Headmaster. And coordinator extracurricular activities that is manager of student. In in the implementation of the extracurricular in Senior High School 2 Bojonegoro there are sixteen extracurricular activities. Extracurricular financing namely by the School Operational Assistance and monthly routine funds from students. The implementation of all the activity have led with national standard education.
\end{abstract}

\section{Keywords: School Based Management, Curriculum Management, Extracurricula}

Abstrak: Penelitian ini bertujuan untuk mendeskripsikan Manajemen Berbasis Sekolah Dalam Pelaksanaan Ekstrakurikuler di SMA Negeri 2 Bojonegoro yang membahas tentang : 1)Manajemen kurikulum di SMA Negeri 2 Bojonegoro; 2) Pengelolaan ekstrakurikuler dalam implementasi Manajemen Berbasis Sekolah di SMA Negeri 2 Bojonegoro; 3)Pelaksanaan ekstrakurikuler dalam implementasi manajemen kurikulum di SMA Negeri 2 Bojonegoro. Jenis penelitian adalah penelitian deskriptif dengan desain penelitian studi kasus. Teknik pengumpulan data adalah observasi, wawancara, dan dokumentasi. Sumber data yaitu Kepala Sekolah, Waka Kurikulum, Waka Kesiswaan, dan Guru Pembina Ekstrakurikuler. Pengecekan keabsahan dengan cara trianggulasi. Hasil penelitian yaitu kurikulum yang dilaksanakan di SMA Negeri 2 Bojonegoro adalah kurikulum 2013. Penanggung jawab Pengelolaan ekstrakurikuler di SMA Negeri 2 Bojonegoro adalah Kepala Sekolah. Dan pengordinir kegiatan ekstrakurikuler yaitu Waka Kesiswaan. Di dalam pelaksanaan ekstrakurikuler di SMA Negeri 2 Bojonegoro terdapat enam belas kegiatan ekstrakurikuler. Pembiayaan ekstrakurikuler yaitu dana BOS dan dana rutin dari komite yang berasal dari SPP siswa. Pelaksanaan segala kegiatan telah mengacu dengan Standar Nasional Pendidikan (SNP)

Kata kunci : Manajemen Berbasis Sekolah, Manajemen kurikulum, Ekatrakurikuler. 
Desentralisasi atau otonomi pendidikan merupakan suatu bentuk reformasi yang perlu dijalankan dengan baik. " $A$ system of education enhancing the autonomy of members at the site level in creating advantageous conditions for participation, improvement innovation, accountability and continuous professional growth" (Gaziel, 1998). Perkembangan ilmu pengetahuan dan teknologi yang begitu pesat juga menuntut adanya pembaruan sistem pendidikan, agar sesuai dengan tuntutan global (Tabrani, n.d.). "Students will be able to collaborate with other students from their own school and with students from other" (Tatnall \& Davey, 2013). Unsur-unsur yang mempengaruhi keberhasilan proses pendidikan dapat diringkas menjadi dua komponen, yaitu komponen yang berasal dalam diri individu yang sedang belajar, dan komponen yang berasal dan luar diri individu (Triwiyanto, 2013). "Educational quality has seldom been at the heart of this policy - the reasons for its introduction are related more to financial and managerial arguments" (Grauwe, 2005). Pemerintah telah melakukan berbagai upaya dalam rangka memberikan harapan bagi kelangsungan dan terkendalinya kualitas pendidikan Indonesia (Hastomo, 2011). Permasalahan pendidikan yang dihadapi oleh bangsa Indonesia dewasa ini salah satunya adalah masih rendahnya mutu pendidikan pada setiap jenjang dan satuan pendidikan, khususnya pada jenjang pendidikan dasar dan menengah (Hamdi, 2011). MBS merupakan wujud restrukturisasi pendidikan di Indonesia (Wijaya, n.d.). "As the name implies, SBM is a government's delegation of school management to the schools themselves, giving them the authority to decide on policy and allocation of resources according to their different needs, and in particular, the needs of students" (Cheung \& Kan, 2009). Implementasi MBS di Indonesia dievaluasi pada tahun 2000, 2002, 2005, dan 2010 (Mistrianingsih, 2003). "School-based management (SBM) practices have been widely implemented by many countries as a major means to enhance school effectiveness and ensure education quality" (Lam, Cheng, \& Ma, 2009). Melalui MBS pemerintah memberikan kesempatan sepenuhnya kepada pihak sekolah untuk mengelola sekolah secara mandiri sesuai dengan kemampuan dan potensi sekolah tersebut (Mufidah, 2017). "SBM has become a major theme and has been largely accepted as a policy initiative in school reforms in a significant number of education systems" (Gamage \& Sooksomchitra, 2004). Pelaksanaan MBS di sekolah secara efektif dan efisien menuntut kepala sekolah untuk menjadi lebih berwibawa dan dapat meningkatkan sikap kepedulian, semangat belajar, disiplin kerja, dan dapat menciptakan suasana kerja yang kondusif. Dalam kerangka inilah MBS tampil sebagai alternatif paradigma baru manajemen pendidikan yang ditawarkan (Hakim, 2016). Selain itu kepala sekolah harus bisa menjalankan fungsinya sebagai manajer di sekolah agar dapat mengatur dengan baik manajemen kurikulum di sekolah tersebut dan segala hal yang terkait seperti kegiatan ekstrakurikuler. "SBM usually involves the creation of school site council sand the decentralization of power and/or school budget to the school sites either from the central/state Government" (Pang, 2008). Kepala sekolah juga harus pandai dalam meningkatkan proses belajar mengajar dengan melakukan supervisi kelas dan membina guru. Selain itu Kepala sekolah juga harus melakukan studi banding antar sekolah agar dapat menyerap ilmu-ilmu dari kepala sekolah yang lain. "Public schools will always exist in some larger policy and administrative context that affects their operations" (Cook, 2008).

Pelaksanaan MBS juga menuntut guru untuk dapat berkreasi dan menciptakan inovasi-inovasi baru dalam meningkatkan manajemen kelas. Selain itu guru juga harus dapat mengorganisasikan kelasnya dengan baik mulai dari jadwal pelajaran, pembagian tugas siswa, kebersihan, dan ketertiban di kelasnya. Di luar kegiatan akademik guru juga harus dapat menjadi pembimbing ekstrakurikuler di sekolahnya.

"The centrality of and the need to reconcile decision-making with responsibility and accountability has given rise to site-based management" (Yuen, 
Lee, \& Law, 2009). Pelaksanaan MBS yang ideal harus sesuai dengan karakteristik MBS dan harus melalui tahap-tahap pelaksanaan MBS. Perencanaan dan persiapan yang baik dalam pelaksanaan MBS akan membantu keberhasilan dari program tersebut, "development of formal procedures for setting school goals and evaluating progress towards these goals" (Yu, 2005).

SMA Negeri 2 Bojonegoro adalah salah satu sekolah yang menerapkan Manajemen Berbasis Sekolah (MBS). Selain memusatkan kegiatan pada akademik sekolah ini juga memusatkan kegiatan-kegiatan non akademik seperti ekstrakurikuler. Banyak kegiatan ekstrakurikuler di SMA Negeri 2 Bojonegoro diantaranya seperti kesenian, olahraga, kegiatan keagamaan, dan kegiatan berbasis sosial kemasyarakatan. Banyak prestasi yang ditorehkan terkait dengan kegiatan ekstrakurikuler.

Berdasarkan sedikit ulasan di atas diketahui bahwa SMA Negeri 2 Bojonegoro adalah sekolah yang menonjolkan kegiatan ekstrakurikuler dan mendukung segala sesuatu terkait kegiatan ekstrakurikuler seperti pembiayaannya. Meskipun banyak beberapa kegiatan ekstrakurikuler di SMA Negeri 2 Bojonegoro yang membutuhkan pembiayaan besar namun pihak sekolah akan mendanai sepenuhnya dan mendukung demi kesuksesan dan kemajuan kegiatan ekstrakurikuler di SMA Negeri 2 Bojonegoro. keseimbangan di dalam hal akademik dan non akademik seperti ekstrakurikuler. Dengan sistem pengelolaan ekstrakurikuler sekolah yang baik SMA Negeri 2 dapat menciptakan siswa-siswa yang berprestasi di bidang non akademik. Di dalam hal ini peneliti ingin mengetahui pengelolaan ekstrakurikuler di sekolah tersebut. Penelitian yang akan diangkat oleh peneliti yaitu penelitian yang berjudul MANAJEMEN BERBASIS SEKOLAH DALAM PELAKSANAAN EKSTRAKURIKULER DI SMA NEGERI 2 BOJONEGORO.

Manajemen Berbasis Sekolah (MBS) adalah terjemahan dari School Based Management, adalah suatu pendekatan politik yang bertujuan untuk me-redisain pengelolaan sekolah dengan memberikan kekuasaan kepada Kepala Sekolah dan meningkatkan partisipasi masyarakat dalam upaya perbaikan kinerja sekolah yang mencakup guru, siswa, Kepala Sekolah, orang tua siswa, dan masyarakat. Manajemen Berbasis Sekolah merubah sistem pengambilan keputusan dengan memindahkan otoritas dalam pengambilan keputusan dan manajemen ke setiap yang berkepentingan di tingkat lokal (local stakeholders).

Manajemen Berbasis Sekolah (MBS) adalah sebagai wujud dari reformasi pendidikan yang meredesain dan memodifikasi struktur pemerintah ke sekolah dengan pemberdayaan sekolah dalam meningkatkan kualitas pendidikan nasional. Pelaksanaan MBS secara efektif dan efisien menuntut kepala sekolah untuk menjadi lebih berwibawa dan dapat meningkatkan sikap kepedulian, semangat belajar, disiplin kerja, dan dapat menciptakan suasana kerja yang kondusif. Selain itu kepala sekolah harus bisa menjalankan fungsinya sebagai manajer di sekolah dalam meningkatkan proses belajar mengajar dengan melakukan supervisi kelas dan membina guru. Kepala sekolah juga harus melakukan studi banding antar sekolah agar dapat menyerap ilmu-ilmu dari kepala sekolah yang lain. Pelaksanaan MBS juga menuntut guru untuk dapat berkreasi dan menciptakan inovasi-inovasi baru dalam meningkatkan manajemen kelas. Selain itu guru juga harus dapat mengorganisasikan kelasnya dengan baik mulai dari jadwal pelajaran, pembagian tugas siswa, kebersihan, dan ketertiban di kelasnya.

Banyak tujuan dari penerapan Manajemen Berbasis Sekolah. Beberapa tujuan dalam penerapan Manajemen Berbasis Sekolah diantaranya yaitu (1) meningkatkan mutu pendidikan melalui kemandirian dan inisiatif sekolah dalam mengelola dan memberdayakan sumber daya dan potensi yang tersedia, (2) meningkatkan kepedulian warga sekolah dalam menyelenggarakan pendidikan melalui pengambilan keputusan bersama, (3) meningkatkan tanggung jawab sekolah kepada orang tua, sekolah, dan 
pemerintah tentang mutu sekolah, dan (4) meningkatkan kompetisi yang sehat antar sekolah untuk pencapaian mutu pendidikan yang diharapkan.

Apabila unsur-unsur yang terlibat di sekolah memahami dan berkontribusi terhadap keberhasilan sekolah, maka model MBS memberikan peluang pada guru dan kepala sekolah mengelola sekolah menjadi lebih efektif, karena rasa saling memiliki semakin tinggi menimbulkan sikap pemanfaatan yang yang lebih baik terhadap sumber daya yang ada untuk mengoptimalkan hasil dan pengelolaan sekolah yang mempunyai kendali akuntabilitas terhadap lingkungan sekolah.

Manajemen kurikulum adalah salah satu komponen di dalam Manajemen Berbasis Sekolah (MBS). Kurikulum dan program pengajaran merupakan bagian dari MBS. Manajemen kurikulum dan program pengajaran mencakup kegiatan perencanaan, pelaksanaan, dan penilaian kurikulum. Perencanaan dan pengembangan kurikulum nasional pada umumnya telah dilakukan oleh Departemen Pendidikan Nasional tingkat pusat. Karena itu level sekolah yang paling penting adalah bagaimana merealisasikan dan menyesuaikan kurikulum tersebut dengan pembelajaran.

Ruang lingkup kegiatan manajemen kurikulum dapat berupa penyusunan program tahunan, penyusunan dan penjabaran kalender sekolah, pembagian tugas mengajar dan tugas lain, penyusunan jadwal pelajaran, pengaturan pemanfaatan sumber dan media pembelajaran, penyusunan rencana pelaksanaan pembelajaran (RPP), suprvisi pembelajaran, pengawasan (pemantauan dan evaluasi), dan pertanggungjawaban (pelaporan).

Panduan mengenai kegiatan ekstrakurikuler terdapat dalam Lampiran Standar Isi berdasar Peraturan Menteri Pendidikan Nasional (Permendiknas No 22 tahun 2006). Dalam buku panduan pengembangan diri, yang dimaksudkan kegiatan ekstrakurikuler adalah kegiatan pendidikan di luar mata pelajaran dan pelayanan konseling untuk membantu pengembangan peserta didik sesuai dengan kebutuhan, potensi, bakat, dan minat mereka melalui kegiatan yang secara khusus diselenggarakan oleh pendidik dan atau tenaga kependidikan yang berkemampuan dan berkewenangan di sekolah. Kegiatan ekstrakurikuler adalah kegiatan-kegiatan siswa diluar jam pelajaran yang dilaksanakan di luar sekolah, dengan tujuan untuk memperluas pengetahuan, memahami keterkaitan antar berbagai mata pelajaran, penyaluran bakat dan minat, dan dalam rangka usaha untuk meningkatkan kualitas keimanan kepada Tuhan YME, kesadaran berbangsa dan bernegara, berbudi pekerti luhur. Kegiatan ekstrakurikuler adalah kegiatan yang diselenggarakan diluar jam pelajaran biasa. Kegiatan ini biasanya dilaksanakan di sore hari bagi sekolahsekolah yang masuk pagi, dan dilaksanakan pagi hari bagi sekolahsekolah yang masuk sore. Kegiatan ini sering dimaksudkan untuk mengembangkan salah satu bidang pelajaran yang diminati oleh sekelompok siswa, misalnya olahraga, kesenian, keagamaan, dan berbagai keterampilan dan kepramukaan.

Kegiatan ekstrakurikuler bukan sekedar tempat menyalurkan hobi siswa saja. Jika disalurkan secara efektif terutama yang berbasis kegiatan fisik, dapat membentuk karakter seorang siswa. Selain itu kegiatan ekstrakurikuler merupakan salah satu unsur dalam upaya membangun kepribadian siswa. Pengembangan kepribadian siswa merupakan inti dari pengembangan kegiatan ekstrakurikuler. Mereka dituntut untuk memiliki kematangan dan keuntungan dalam lingkup dunia hunian mereka sebagai pelajar. Mereka mampu mengembangkan bakat dan minat, menghargai orang lain, bersikap kritis, berani mencoba hal yang positif, peduli terhadap lingkungan, sampai pada melakukan kegiatan-kegiatan intelektual dan ritual keagamaan.

Kegiatan ekstrakurikuler memiliki tujuan pengembangan bakat dan minat serta pengetahuan khusus bagi peserta didik yang pelaksanaannya dilakukan diluar jam pelajaran. 


\section{METODE}

Dalam penelitian ini peneliti akan menggunakan pendekatan kualitatif. Peneliti melakukan eksplorasi dan penilaian baik secara menyeluruh dan terfokus untuk memperoleh data yang lengkap dan rinci mengenai objek yang diteliti.

Jenis penelitian yang digunakan adalah penelitian deskriptif. Yaitu penelitian yang digunakan untuk menggambarkan, menjelaskan dan menjawab persoalan-persoalan tentang fenomena dan peristiwa yang terjadi saat ini.

Desain penelitian ini yaitu studi kasus. Studi kasus adalah metode untuk memahami individu atau suatu hal yang dilakukan secara integrative dan komprehensif agar diperoleh pemahaman yang mendalam. Dalam hal ini peneliti melakukan studi kasus mengenai kegiatan ekstrakurikuler dalam implementasi MBS. Peneliti melakukan pengumpulan data secara komprehensif dengan tujuan memperoleh informasi dan pemahaman yang mendalam tentang suatu isu dan kasus mengenai kegiatan ekstrakurikuler di dalam MBS.

Di dalam penelitian ini untuk memperoleh data yang sesuai dengan keperluan penelitian, peneliti menggunakan teknik pengamatan langsung (Observasi), wawancara, dan dokumentasi.

Menjamin keakuratan dan keabsahan data penelitian sangatlah penting. Dalam hal ini ada beberapa tekhik keabsahan data. Terdapat empat teknik pengabsahan data diantaranya adalah kredibilitas, depentabilitas, transferabilitas, dan konfirmabilitas.

\section{HASILDAN PEMBAHASAN}

Kurikulum yang dilaksanakan di SMA Negeri 2 Bojonegoro adalah kurikulum 2013 dimana perencanaannya yaitu Kepala Sekolah dan Waka Kurikulumdibantu oleh tim penyusun kurikulum dalam pembuatan RKAS. Pelaksanaannya yaitu guru-guru melaksanakan tugas yang sudah terjadwal sesuai dengan aturan kurikulum. Dan dalam evaluasinya dilaksanakan disaat akhir semester dan saat kegiatan semester berlangsung sebagai tindak lanjut. Segala kegiatan terkait perencanaan, pelaksanaan dan evaluasi telah mengacu pada PP RI Nomor 32 Tahun 2013.

Penanggung jawab semua kegiatan induk termasuk ekstrakurikuler adalah Kepala Sekolah dan tugas Kepala Sekolah menentukan kebijakan dalam kegiatan tersebut. Wewenang untuk mengordinir kegiatan ekstrakurikuler diberikan kepada Waka Kesiswaan.

Dalam kaitannya dengan pelaksanaan ekstrakurikuler dalam implementasi manajemen kurikulum di SMA Negeri 2 Bojonegoro terdapat enam belas kegiatan ekstrakurikuler di SMA Negeri 2 Bojonegoro. Kegiatan ekstrakurikuler tersebut diantaranya yaitu Bola Voli, Paduan Suara, Sepak Bola/Futsal, Sepak Takraw, PMR, Paskibraka, Seni Karawitan, Atletik, Sinematografi, Hadrah/Samroh, Teater, Seni Islami (Kaligrafi, Tilawah), Bola Basket, Pramuka, Seni Tari, dan Jurnalistik. Tujuan umum kegiatan ekstrakurikuler di SMA Negeri 2 Bojonegoro adalah untuk mengexplore dan menumbuhkembangkan potensi yang ada di dalam diri siswa baik potensi di bidang akademik dan non akademik. Dalam bidang akademik contohnya ekstrakurikuler paduan suara atau teater dimana ekstrakurikuler tersebut juga dapat dibilang termasuk dalam bidang akademik khususnya dalam pelajaran kesenian sehingga sedikit banyak bahwa kegiatan ekstrakurikuler tersebut dapat berpengaruh dalam bidang akademik, dan dalam bidang non akademik contohnya seperti kegiatan ekstrakurikuler paskibraka, PMR, dll. Untuk manfaat umumnya kegiatan ekstrakurikuler memberikan pengetahuan kepada siswa tentang kegiatan ekstrakurikuler tersebut. Dalam kegiatan ekstrakurikuler terdapat penanggungjawab sendiri-sendiri dalam setiap kegiatannya. Waktu pelaksanaan kegiatan ekstrakurikuler diluar jam sekolah. Dan untuk pendanaan atau pembiayaan kegiatan ekstrakurikuler menggunakan dana BOS sekolah serta dipadukan dengan dana rutin (SPP). 
KESIMPULAN

Terdapat beberapa kesimpulan diantaranya :

1. SMA Negeri 2 Bojonegoro adalah salah satu sekolah yang telah menerapkan Kurikulum 2013 yang di dalam kegiatan perencanaannya Kepala Sekolah dan Waka Kurikulum dibantu oleh tim pengembang atau penyusun Kurikulum. Dalam kegiatan pelaksanaannya para guru dengan baik melaksanakan tugasnya sesuai aturan kurikulum yang berlaku dan untuk evaluasinya dilaksanakan setiap kegiatan semester berlangsung dan setiap akhir semester, selain itu membuat evaluasi diri sekolah dimana selama satu tahun ajaran melihat tentang kekuatan dan kelemahan serta kekurangan suatu kurikulum yang diterapkan, kegiatan evaluasi ini juga biasa disebut dengan analisis SWOT. Kegiatan terkait dengan kurikulum seperti perencanaan, pelaksanaan, dan evaluasi telah mengacu kepada Peraturan Pemerintah Republik Indonesia Nomor 32 Tahun 2013 dan didukung oleh pendapat-pendapat pakar di dalam dunia pendidikan.

2. Dalam pengelolaan ekstrakurikuler dalam implementasi Manajemen Berbasis Sekolah di SMA Negeri 2 Bojonegoro penanggung jawab induk segala kegiatan di SMA Negeri 2 Bojonegoro adalah Kepala Sekolah. Sedangkan pelimpahan segala urusan di dalam bidang kegiatan ekstrakurikuler di SMA Negeri 2 Bojonegoro diserahkan kepada Waka Kesiswaan. Dalam hal ini Kepala Sekolah berperan sebagai penanggungjawab serta penentu kebijakan yang bertugas menentukan segala kegiatan estrakurikuler yang sesuai dengan bakat dan minat siswa maupun siswi di SMA Negeri 2 Bojonegoro. Selain itu Terkait pengelolaan ekstrakurikuler di SMA Negeri 2 Bojonegoro Waka Kesiswaan dalam hal ini berperan sebagai pengordinir, pelaksana, pengawas, dan pengevaluasi setiap kegiatan ekstrakurikuler keseluruhan di SMA Negeri 2 Bojonegoro.
3. Terdapat enam belas kegiatan ekstrakurikuler di SMA Negeri 2 Bojonegoro. Tujuan umum kegiatan ekstrakurikuler di SMA Negeri 2 Bojonegoro adalah untuk mengexplore dan menumbuhkembangkan potensi yang ada di dalam diri siswa baik potensi di bidang akademik dan non akademik. Manfaat umumnya kegiatan ekstrakurikuler memberikan pengetahuan kepada siswa tentang kegiatan ekstrakurikuler tersebut dan dapat mengantarkan siswa menuju prestasi. Dalam kegiatan ekstrakurikuler terdapat penanggungjawab sendiri-sendiri dalam setiap kegiatannya. Waktu pelaksanaan kegiatan ekstrakurikuler diluar jam sekolah. Untuk pendanaan atau pembiayaan kegiatan ekstrakurikuler menggunakan dana bos sekolah serta dipadukan dengan dana rutin (SPP).

\section{DAFTAR RUJUKAN}

Cheung, S. M. C., \& Kan, ÆE. F. L. F. (2009). Teachers 'perceptions of Incorporated Management Committees as a form of schoolbased management in Hong Kong. 139-148.

https://doi.org/10.1007/s12564-0099012-5

Cook, T. D. (2008). School Based Management: A Concept of Modest Entitivity with Modest Results. (March 2007), 129-145. https://doi.org/10.1007/s11092-0079049-0

Gamage, D. T., \& Sooksomchitra, P. (2004). Decentralisation And SchoolBased Management In Thailand David $T$. Gamage and Pacharapimon Sooksomchitra Decentralisation and education reform issues in Thailand Since the late 1980s, the decentralisation and devolution of authority to school level have . 289-305.

Gaziel, H. (1998). School-Based Management As A Factor In School Effectiveness Arguments for 
decentralization In recent years there has been a growing international trend toward decen- tralization, devolution and greater autonomy for schools in the public educa- tion syste. 44(4), 319-333.

Grauwe, A. D. E. (2005). School-Based Management: Learning From International Experiences Anton de Grauwe. 269-287. https://doi.org/10.1007/s11159-0057733-1

Hakim, M. N. (2016). Nidhomul Haq Vol 1 No: 2 Juli 2016 Implementasi Manajemen Berbasis Sekolah Dalam Mewujudkan Sekolah Islam Unggulan Muhammad Nur Hakim / Implementasi MBS Dalam Mewujudkan Sekolah Islam Unggulan Nidhomul Haq Vol 1 No: 2 Juli 2016 Muhammad Nur Hakim / Impl. 1, 104-114.

Lam, S. fong, Cheng, R. W. yi, \& Ma, W. Y. K. (2009). Teacher and student intrinsic motivation in project-based learning. Instructional Science, 37(6), 565-578.

https://doi.org/10.1007/s11251-0089070-9

Mistrianingsih, S. (2003). Peran kepala sekolah dalam implementasi manajemen berbasis sekolah.

Mufidah, N. (2017). Peran Manajer Kepala MIN Jejeran Bantul dalam Implementasi Manajemen Berbasis Madrasah. 2, 45-62.

Pang, I. (2008). School-based management in Hong Kong: centralizing or decentralizing. 17-33. https://doi.org/10.1007/s10671-0079041-y

Pemerintah, K., Satuan, P., \& Keagamaan, P. (n.d.). No Title.

Sekolah, M. B. (2011). (Studi pada di SMP Negeri 6 Kisaran Kabupaten Asahan). 2(1), 130-159.

Tatnall, A., \& Davey, B. (2013). The Ultranet and School Management: Creating a New Management Paradigm for Education. 163-170.
Triwiyanto, T. (2013). Pemetaan mutu manajemen berbasis sekolah melalui audit manajemen pendidikan. (1).

Wijaya, D. (n.d.). Model Balanced Scorecard Dalam Implementasi Manajemen Berbasis Sekolah ( Mbs ). 45-58.

Yu, H. (2005). In Hong Kong: Recent Development And Future. 253-275. https://doi.org/10.1007/s10833-0055458-3

Yuen, A. H. K., Lee, M. W., \& Law, N. (2009). School leadership and teachers ' pedagogical orientations in Hong Kong: A comparative perspective. 381-396. https://doi.org/10.1007/s10639-0099091-2 